\title{
Small-bowel perforation caused by AdvanCE capsule endoscopy delivery device
}

We report herein the case of a 58-yearold-woman who was admitted for hematochezia with acute anemia (hemoglobin $9 \mathrm{~g} / \mathrm{dL}$ ). She had a history of small-bowel adenocarcinoma (T3NOMO) complicating celiac disease; this had been treated by a Whipple procedure 12 years previously, with complete remission since then. She was taking anticoagulants following mitral valve replacement with a mechanical valve, with international normalized ratio (INR) of 2 at the time of admission.

Computed tomography (CT) showed no intestinal abnormalities. Upper and lower endoscopies showed normal findings. Small-bowel video capsule endoscopy (VCE) was performed, using the AdvanCE capsule endoscope delivery device (ACEDD; US Endoscopy, Mentor, Ohio, USA) because of the patient's intestinal loop anatomy. The procedure was carried out without any obvious complication. Of note, the upper endoscopy was done without anesthesia, and poor tolerance led to quick removal of the scope after capsule release.

Several hours later, the patient complained of acute abdominal pain. CT showed a perforation close to the gastrojejunal anastomosis. Laparotomy revealed a small-bowel perforation $10 \mathrm{~cm}$ below the anastomosis with the capsule impacted in the mesentery. The VCE reading ( $\bullet$ Video 1 ) showed an immediate perforation induced by the
ACEDD before release of the capsule; this was confirmed by the intraoperative findings ( Video 1 ). The outcome was favorable after resection and anastomosis of the perforated area.

The ACEDD was described as safe in a small case series of 16 patients in 2007 by Holden et al. [1]. To our knowledge this is the first case of perforation caused by this device.

\section{Endoscopy_UCTN_Code_CPL_1AI_2AB}

Competing interests: None

\section{Marion Simon', Sandrine Barge ${ }^{2}$, Florence Jeune $^{3}$, Helene Corte ${ }^{3}$, Pierre Cattan $^{3}$, Jean-Marc Gornet ${ }^{1}$}

${ }^{1}$ Department of Gastroenterology, St. Louis Hospital, AP-HP Paris, France

${ }^{2}$ Department of Gastroenterology, Robert Ballanger Hospital, Aulnay-sousBois, France

${ }^{3}$ Department of General, Endocrine and Digestive Surgery, St. Louis Hospital, AP-HP Paris, France

\section{Reference}

1 Holden JP, Dureja P, Pfau PR et al. Endoscopic placement of the small-bowel video capsule by using a capsule endoscope delivery device. Gastrointest Endosc 2007; 65: $842-$ 847

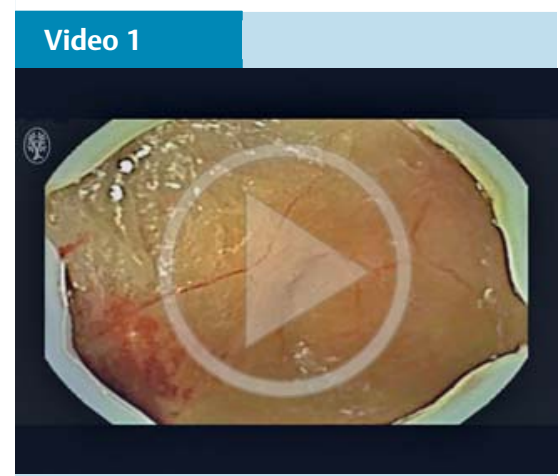

Small-bowel perforation by the AdvanCE capsule endoscopy delivery device (ACEDD). The capsule endoscopy video shows an immediate perforation below the gastrojejunal anastomosis, caused by the rigid extremity of the ACEDD, with complete stalling of the capsule thereafter. Capsule impaction in the perforated area is confirmed intraoperatively.

Bibliography

DOI http://dx.doi.org/

10.1055/s-0042-118164

Endoscopy 2016; 48: E342

(c) Georg Thieme Verlag KG

Stuttgart · New York

ISSN 0013-726X

Corresponding author

Jean-Marc Gornet, MD

Service de Gastroentérologie

1 Avenue Claude Vellefaux

Hôpital Saint Louis

75010 Paris

France.

Fax: +33-1-42499168

jean-marc.gornet@aphp.fr 